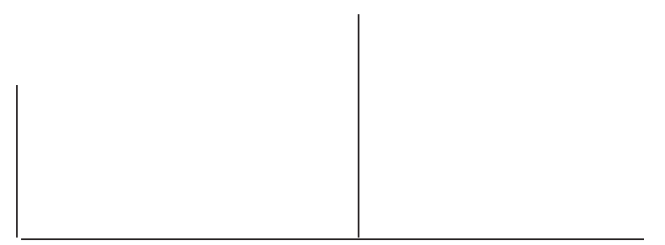

Rev. Latinoam. Psicopat. Fund., IX, 3, 496-507

\title{
Elementos para uma teoria da vergonha na psicose*
}

\author{
Delphine Scotto di Vettimo
}

\begin{abstract}
Este artigo propõe uma discussão crítica da problemática da vergonha considerada desde a vertente social onde faz sintoma e aonde vem marcar a ferida do ideal. Com efeito, a vergonha é primeiramente um sentimento social: aparece geralmente em reação ao olhar do outro e assinala o fracasso da confirmação narcisista. A hipótese proposta postula que no trabalho clínico junto a sujeitos confrontados com uma experiência psicótica, a expressão da vergonha como prova ontológica do olhar do Outro constituiria uma tentativa do sujeito de provar-se como tal. Esta reflexão insiste, através de uma evocação clínica, na concorrência entre vergonha, psicose e relação social.

Palavras-chave: Relação social, narcisismo, psicose, sentimento de vergonha
\end{abstract}

* Tradução para o português, de Monica Seincman. 
Pela vergonha, o sujeito testemunha (...) permanecer sujeito. Ele se reconstrói, em torno da ferida de ideal, testemunhando continuar sofrendo de ideal.

Paul-Laurent Assoun, 1999, p. 109.

\section{Introdução}

O Dicionário da língua francesa, de Émile Littré, propõe a seguinte definição de vergonha: "Desonra, vergonha, humilhação" e também retoma, em termos praticamente similares, a definição do Dicionário da Academia Francesa que enuncia assim: "Confusão, perturbação, sentimento doloroso estimulado na alma pela idéia de alguma desonra que se sofreu ou que se teme sofrer ou que se sinta apenas a seus próprios olhos”. Convém notar que a distinção entre o psíquico e o social não está claramente estabelecida, distinção que é capital no estudo da vergonha. O uso de termos tais como "confusão", "sentimento” e "temor" assinala o caráter psíquico da vergonha em relação a seu caráter social. É bom retomar este estatuto bastante paradoxal da vergonha. Fixemos, por ora, que a vergonha é antes de tudo um sentimento social: ela aparece na maioria das vezes em reação ao olhar do outro e vem marcar "o fracasso da confirmação narcísica” (Miollan, 1998, p. 163). Este primado do olhar na experiência da vergonha encontraria sua hipótese interpretativa no fato de que ela teria sua origem no olhar do Outro, olhar que revelaria para o sujeito seus próprios limites, sua incompletude; em outras palavras, desvelaria a defasagem insustentável entre a imagem narcísica de si feita de perfeição e uma imagem de insuficiência e imperfeição reconhecida no olhar do Outro.

É aí que nos situamos na perspectiva lacaniana clássica que postula, a propósito do Outro, que “... é a partir dele que o sujeito se constitui, pois 


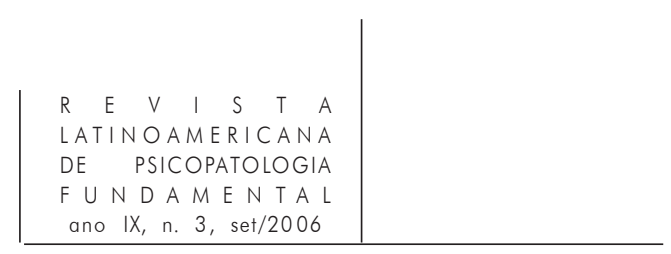

é do Outro que o sujeito recebe inclusive a mensagem que emite” (Lacan, 1960, p. 807). A descarga fulgurante de vergonha tal como descrita em Sartre em uma perspectiva fenomenológica, testemunha com muita exatidão esta experiência emocional em que uma parte do mais íntimo de si se encontra brutalmente exposto, verdadeiro desnudamento do sujeito que o confina em um caos narcísico. Na experiência da vergonha, o efeito de transparência que se sente é a tradução mais explícita, que não poderia ser melhor expressa do que pelo vocábulo, bastante corriqueiro, "desnudamento". Este rebaixamento a uma função de objeto engendra uma grande desordem no sujeito, pois ele ainda é presa de uma incerteza narcísica angustiante. Neste sentido, a vergonha constitui uma experiência subjetiva singular - a de um sujeito bruscamente revelado em sua intimidade de pensamento, pela presença de um olhar do qual é impossível se furtar. Como afeto, a vergonha é inicialmente social, estreitamente ligada ao olhar do outro, assim como expressão da manifestação de uma reivindicação singular. Toda a questão colocada pela vergonha se refere ao seu caráter fundamentalmente intersubjetivo, a saber: ela acompanha um fracasso diante de testemunhas e leva a querer se esconder.

Este trabalho é uma reflexão elaborada, de um lado a partir da questão do estatuto metapsicológico da vergonha na obra freudiana, de suas manifestações e de seu tratamento psicoterápico (Scotto Di Vettimo, 2001), de outro, a partir da questão da apreensão da vergonha no campo da psicose. Trata-se aqui, a partir de uma situação clínica, de questionar a experiência da vergonha em um sujeito e mais amplamente de interrogar a problemática da vergonha considerada sob a vertente social na qual faz sintoma.

A referência à vergonha não é rara na obra de Freud e é apreendida globalmente como índice de um funcionamento sob o modo narcísico. Em A interpretação dos sonhos (1900) $)^{1}$ Freud assinala o caráter especular da vergonha, que se apóia no olhar: a vergonha se alimenta da incompletude imaginária que constitui o próprio objeto do interesse e do amor narcísico, em referência a uma representação de si e da experiência que representa o fato de se reconhecer imperfeito, limitado, faltante, ou seja, submetido à experiência da castração.

1. No texto do Gênese, o nascimento do sentimento de vergonha é contemporâneo à descoberta da nudez: Adão e Eva, após cometerem o pecado original, descobriram-se nus... e envergonhados. A teoria psicanalítica freudiana terá o texto bíblico como ponto de partida do sentimento de vergonha, assim como da angústia e da culpa: "É por isso”, observa Freud em A interpretação dos sonhos (1900), "que no paraíso os homens estão nus e não sentem vergonha alguma, até o momento em que a vergonha e a angústia são despertadas, em que são expulsos e começam a vida sexual e a civilização". 
Indo além, na obra de Lacan, a vergonha é considerada ontológica já que é articulada ao homem. Esta hipótese parece se coadunar com a hipótese freudiana sobre a vergonha. Fundamentando-se nestas considerações, a emergência da vergonha não se restringiria apenas, portanto, ao sentimento de valor e de auto-estima, mas abarcaria também, e sobretudo, o sentimento de identidade, cujas fissuras e rupturas a vergonha revelaria. É justamente neste caso que se trata de pensar a existência da vergonha no psicótico. Esta conviçcão constitui uma linha de escuta do discurso de sujeitos confrontados a uma experiência psicótica com hospitalização psiquiátrica. Quando uma fala pode ser enunciada em seguida a isso, é possível constatar que ela se desenvolve na transferência para dizer um tipo de indigência. Falar de sua problemática psicótica é, então, antes de tudo, dizer-se diferente, deslocado, desvalorizado e irremediavelmente danificado. Por outro lado, expressões tais como "estranhamento", “errância”, “exclusão”, tecem as conversas com estes pacientes; expressões que testemunhariam esse encobrimento da realidade por um real que submerge o aparelho psíquico e suas construções imaginárias e que assinalam, em um prazo mais ou menos curto, o deslizamento da potencialidade psicótica para a descompensação psicótica (Aulagnier, 1984, p. 9-21). Esta involução inerente à entrada na psicose perderia o sentido daquilo que, na experiência da vergonha, funcionaria como traço, sustentando assim o essencial de sua questão subjetiva, ou seja, sua chegada imprevista como salvaguarda narcísica.

Na obra intitulada O preconceito e o ideal (1999), Assoun propõe considerar “... os exilados no sentido literal - deslocalização geográfica e social - e os exilados no sentido figurado - dessubjetivação e mal-estar da interioridade” (p. 114). É justamente este último argumento que nos interessará aqui no que ele revela da experiência psicótica como prova de dessubjetivação e de exílio interior. Como um sujeito pode ser confrontado, do interior, com este sentimento de estar em outro lugar, estrangeiro, exilado? Uma clínica do exílio no campo da psicose poderia interrogar esta experiência de estranhamento que se refere a uma posição subjetiva. Falar de "exílio interior" (ibid.) permitiria designar um tipo de metáfora: aquela que designa o psicótico para esta experiência - na maioria das vezes aterrorizante - de despossessão de si, de exclusão e de dessubjetivação.

Fiquei sensibilizada - como outros clínicos - com a expressão de sentimentos de vergonha que podiam colorir o relato de experiências de sujeitos psicóticos e que acima de tudo pareciam invadir, invalidar, o conjunto de sua vida psíquica, de sua experiência relacional e social. Não apenas a vergonha ganhava, invadia a esfera subjetiva, mas a persistência se tornava repetição na encenação de relatos de situações produtoras de vergonha para estes sujeitos. Por que a experiência psicótica produz vergonha no sujeito? A hipótese aqui 


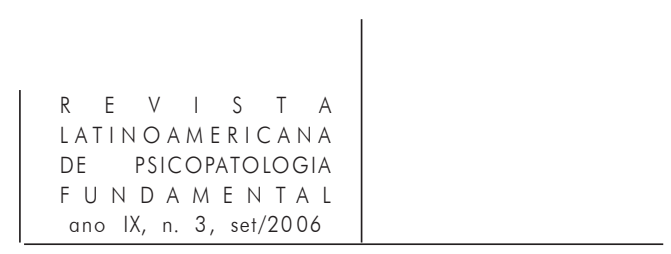

enfocada postula que, no trabalho clínico, a expressão da vergonha como prova ontológica do olhar do Outro constituiria uma tentativa do sujeito de se experimentar como tal e de manter um laço social. Com efeito, para o sujeito, a expressão da vergonha é portadora de uma acepção precisa, ela é para o clínico primeiramente índice e mensageira de uma significação particular atribuída à fala (Scotto Di Vettimo e Jacobi, 2003, p. 112). Este questionamento encontra alguns prolongamentos do ponto de vista de seu uso no discurso: por exemplo, um sujeito que diz que sente vergonha não está necessariamente afetado pela vergonha. Em outras palavras, o uso do termo vergonha pelo sujeito não prejulga a existência do afeto. Como o escreve Jacobi (2000), "se ela é exposição, exibição, a fala se diferencia radicalmente daquilo que ela evoca” (p. 151). A partir de então, a questão que, para o clínico, se coloca, é justamente discernir a experiência da vergonha de um sujeito para além dos termos do discurso que a acompanha. É verdade que o uso deste termo não remete a um diagnóstico, a uma nosografia. Mas merece explicação o salto que consiste em afirmar a presença da vergonha para um sujeito a partir da ocorrência deste termo em seu discurso.

Proponho, neste artigo, situar os desenvolvimentos e conexões deste posicionamento a partir de uma situação clínica de ruptura mais ou menos radical: o discurso psicopatológico de uma jovem mulher que traduz sua entrada na psicose. Com este intento, um breve extrato do trabalho terapêutico permitirá, por um lado, voltar à hipótese de trabalho indicada no início deste artigo e, por outro, dirigir uma atenção específica para certas modalidades do processo psicótico e da experiência da vergonha que lhe é contingente.

Uma jovem que vamos chamar Magali foi recebida em uma oficina terapêutica de inserção socioprofissional após uma hospitalização psiquiátrica por “descompensação psicótica” que durou 12 meses.

\section{Vinheta clínica}

\section{Dados biográficos}

Magali, 32 anos de idade, é a caçula de uma fratria de dois irmãos: ela tem um irmão mais velho que faz parte do primeiro escalão em uma empresa. Ela passa regularmente os fins de semana na casa de seus pais, ambos aposentados.

Os elementos históricos e clínicos recolhidos fazem menção a um "mau entendimento familiar" e falam - de acordo com Magali - "de uma infância antes difícil, uma boa aluna sempre retraída e descrita como apática”. 
Os primeiros distúrbios psicopatológicos apareceram quando Magali contava 18 anos e foi inscrita no primeiro ano da Faculdade de Direito. Ela apresenta nesse período um desinteresse intelectual, idéias delirantes de transformação corporal, um isolamento afetivo e social, assim como manifestações de violência em relação à família. Após vários meses de hospitalização em um serviço psiquiátrico, o diagnóstico médico estabelecido foi o seguinte: psicose esquizofrênica.

\section{Encontros clínicos}

À sua chegada na oficina terapêutica, Magali solicita entrevistas em virtude de questionamentos obsessivos sobre sua auto-imagem (particularmente seu corpo e sua pele), tudo sob o fundo de inibições fóbicas que invadiam seu campo de atividades: ela temia ficar na frente das pessoas, neste caso dos outros pacientes, pois receava que esses rissem dela. Fiquei inicialmente chocada com sua aparência: ela tem os cabelos muito curtos e traz um amplo macacão de jeans cheio de bolsos. Seu corpo parece literalmente desaparecer nesses trajes grandes demais. A primeira entrevista começa assim: "Minha doença é grave: engordo e tenho a tendência a me abandonar”. A entrevista será pontuada por longos silêncios durante os quais Magali imprime a seu corpo um balanceio para frente e para trás, sempre mantendo seus olhos fixos no assento.

Nas entrevistas que se seguirão, Magali fala com bastante facilidade de si mesma: como ela era "antes" e como, em pouco tempo, sua vida mudou. Ela se lembrava de ter sido uma criança "como as outras”, mas desde essas várias hospitalizações ela diz ter perdido muita coisa. A origem de sua doença, segundo ela, está ligada sem dúvida à ausência de amor parental; ela diz: "Meus pais não são ligados a mim, isto me deixa em desvantagem e faz com que eu fique doente, principalmente bulímica. Pior ainda, isto levou à minha inação e meu debilitamento pelas ruas da cidade". Em suas lembranças, os primeiros sintomas teriam aparecido quando estava na universidade: "A realidade e as trocas sociais", diz ela, "ficaram cada vez mais difíceis: uma fronteira foi imposta, um limite. O que eu vivia catastroficamente era a minha solidão e minhas relações com os outros. As trocas humanas se tornavam cada vez mais pobres”. Cada um de seus relatos é marcado por mal-estares recorrentes, traz um clima de confusão e impotência. Ela descreve então uma perda progressiva de confiança em si mesmo, um fechamento e um isolamento social cada vez mais significativos: "Eu me sentia em uma situação frágil por causa de minha saúde abalada, da desigualdade social e desta solidão que me pesava”. É então que ela conta o início de sua errância pelas ruas da cidade: “Como reação, saí pela cidade, eu errava, tudo isso 


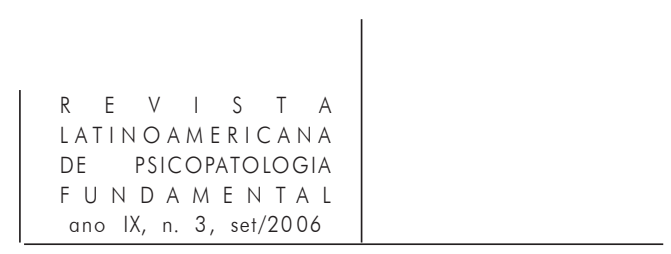

provocou um desvirtuamento". A descompensação virá dois meses depois. Ela será então Hospitalizada sob Ordem de um Terceiro (HDT - Hospotalisée à la Demande d’un Tiers), no caso seu pai, em um serviço psiquiátrico.

Algum tempo depois, ela poderá abordar com mais precisão uma experiência de vergonha que associa aos efeitos de perda, subjetiva e narcísica, que sua doença provocou. Eis o que ela diz: "Sinto permanentemente vergonha de minha descompostura, sou malvestida e ignorante. Minha doença provocou uma degradação íntima. Tenho vergonha de mim”.

É assim que toda uma série de vergonhas em registros muito variados vai se desdobrar ao longo das entrevistas. O sentimento de vergonha parece reunir essas experiências da infância e da adolescência. Vergonha do desamor parental, vergonha de se sentir diferente dos outros, vergonha de ter sido maltratada, vergonha de seu fracasso universitário. Mas, mais fundamentalmente, a questão que se coloca para Magali, em relação à sua doença e a seus efeitos de dessubjetivação, é justamente a de suas conseqüências radicais: mudança das capacidades físicas e intelectuais, quando ela percebe que não pode mais fazer o que fazia antes (luto dos estudos principalmente), tudo o que a ligava aos outros de sua geração (perda dos companheiros da universidade), tudo o que os pais esperavam dela (eles desejavam que ela fizesse a universidade), amavam nela.

\section{Encontro entre a (h)ontologia* e a clínica}

A análise deste fragmento clínico permite agora voltar à afirmação indicada no início deste artigo, a saber: uma das funções da vergonha é experimentar-se como sujeito. Retomar as palavras da experiência psicótica que visa o âmago do ser, estas mesmas palavras que testemunham este sofrimento vivo e alienante "O problema”, confiava Magali, "é este isolamento da minha pessoa, o fato de querer viver em grupo e ser rejeitada, excluída pelo grupo" - nos leva à exploração do sentimento de estranhamento e de exclusão próprios da psicose. É sobre este fundo de sofrimento inerente ao processo psicótico, sobre a impossibilidade de se tornar senhor que Assoun (1999) evoca a "sensação paradoxal de estar incluso em um espaço que, hostil ou 'acolhedor' em si mesmo, não permite a seu outro aí se reconhecer, portanto o exclui” (p. 114). É isto que Magali testemunha quando diz: "Os outros são diferentes de mim, eles têm

* Lacan cria este neologismo com o cruzamento de honte (vergonha) + ontologie (ontologia). (N. da T.) 


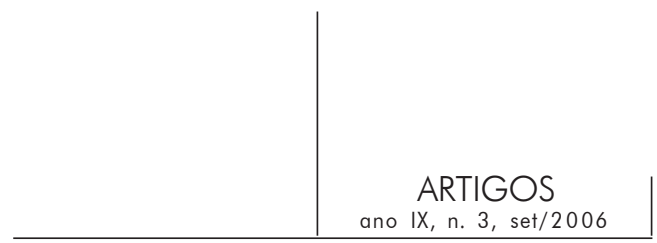

algo a mais”. O sentimento de exclusão social viria atestar um momento em que vacila a certeza de um laço social: "Não há exclusão social sem um sujeito que produza o gesto de se excluir” (p. 36), afirma Assoun. É justamente o que relatava Magali para justificar a manutenção deliberada de seu isolamento; por exemplo, em relação aos outros pacientes da oficina que organizam noitadas e saídas para as quais era convidada, mas que declinava sistematicamente. Esta convicção de um preconceito social como “desvantagem” para retomar suas próprias palavras era reforçada por um outro preconceito - com vocação delirante - expresso da seguinte maneira: “Eu procuro uma verdade sobre a minha vida pessoal que não me querem conceder, uma verdade sobre minha identidade, minha vida biológica... as pessoas sabem algo sobre mim que eu ignoro. É um estratagema dirigido contra mim”. Na concepção do aparelho psíquico tal como articulada na segunda tópica, Freud delimitará o campo da psicose em um conflito entre o ego e o mundo externo. A perda da realidade que é o corolário dos conflitos entre a instância egóica e o mundo externo, aconteceria no início da psicose; em eco, um substituto de realidade viria no lugar de algo forcluído.

O processo psicótico refere-se à questão da passagem ou, antes, à questão da travessia de um experiência-limite que Magali testemunha quando diz: “Quando caí doente, saí pela cidade, eu errava. Minha doença trouxe minha inação e meu debilitamento”. A errância por esse território desconhecido - ao mesmo tempo subjetivo e espacial - desértico, austero, sem limite, levará Magali, por várias semanas, a apenas descobrir um deserto vazio de qualquer encontro humano, enquanto ela erra pelas ruas da cidade noite e dia. A vergonha poderia vir então da incapacidade de encontrar, de fazer aparecer os traços comuns, os significantes partilhados, que são a própria expressão do reconhecimento do laço com o outro. Nesta perspectiva, pode-se lançar a hipótese da vergonha como apelo irreprimível a obter resposta para esta questão do laço com o outro semelhante, a vergonha como apelo ontológico. Para responder a esta suposição, proponho dois trabalhos de Lacan para esboçar uma compreensão da vergonha como inscrição intrínseca na própria condição humana.

Na obra de Lacan (1969-1970), a “hontologia” designa na dimensão ontológica o real que é causa do sujeito. É isto o que o encontro traumático descobre em sua confrontação com o real da morte, do horror, do indizível, do insustentável, para além de qualquer possibilidade de simbolização. Marcada por seu encontro com o real, a vergonha vai imprimir sua marca. É quando é experimentada em sua ligação com o originário e em relação escópica com o outro semelhante: o real apreendido no olhar de um outro. Ao mesmo tempo, esta vergonha ontológica permite ao sujeito experimentar-se como tal, pois este olhar que se lhe endereça e do qual é mira, manifesta em primeiro lugar a presença do Outro. Para Lacan (1953-1954), a consideração e a existência desse olhar 


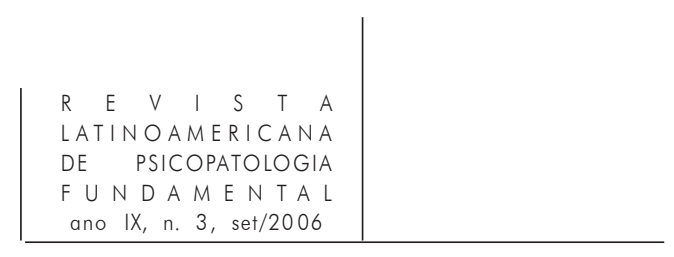

Outro modificará o posicionamento, o estatuto do sujeito - olhado - que a partir de então torna-se objeto do olhar do Outro: "Esta janela, se está um pouco escuro, e se tenho razões para crer haver alguém por detrás, é daqui por diante um olhar" (p. 240). Esta formulação encontra uma ressonância ontológica e assinala a estrutura fenomenológica da vergonha. Em outras palavras, é na relação do sujeito com o Outro, neste olhar Outro que ele vai se ver e se sentir existir; o Outro dá consistência ao sujeito em seu percurso desejante: "Pois o desejo em sua raiz e essência é o desejo do Outro...” (Lacan, 1960-1961, p. 212). Quando o processo psicótico veio fixar o sujeito em sua esfera psíquica e obturar sua relação com a realidade, um limite é irremediavelmente transposto: a vergonha seria o reconhecimento desta transposição, ela testemunharia a luta com morte simbólica que é esta da ancoragem psicótica e do encontro com o real - a morte próxima - expressa nestes termos por Magali: “Tive um fechamento de consciência, como uma negação de minha consciência em relação à realidade”. A vergonha estaria ligada a um duplo exílio desta fronteira entre o tempo da infância e o da adolescência, entre o tempo anterior à entrada na psicose e o do início da doença que Magali evocava do seguinte modo: "Tenho a impressão de ter deixado um passado que nunca mais encontrarei. Tenho dificuldade em conservar estes traços... eles não mais me pertencem, é como se tivesse havido uma pilhagem íntima”. Confrontada a esta prova que a torna estranha e estrangeira a si mesma, a vergonha ontológica como experiência de ser permitir-lhe-ia provar-se como sujeito enquanto ela se sente cada vez mais em uma errância psíquica, a meio caminho, diz ela, entre o mundo "de antes que nunca mais encontrarei” e este universo estranho, face obscura da Lua, fragmentos parcelares psíquicos nos quais, afirmava ela, "eu não vivo mais como os outros. Sinto-me abaixo dos outros, é uma triste realidade. Há uma degradação íntima”.

A vergonha, que tem um valor na economia e na dinâmica psíquicas do sujeito, viria aqui se alojar nesse intervalo, nesse entremeio, entre neurose e psicose, entre presença e ausência, entre alteridade e estranhamento. Neste sentido, quando o ser humano é confrontado a uma forma de indigência contingente à sua entrada na psicose - "Minha doença levou ao meu debilitamento" confiava Magali -, a vergonha ontológica referir-se-ia à própria essência do homem e àquilo que funda sua pertença à espécie humana; com efeito, no sentido lacaniano, a vergonha é ontológica "já que está articulada ao homem". ${ }^{2}$ No encontro do real do trauma, do horror e da morte, o sujeito vai se chocar com o impensável, com o impossível, o irrepresentável. O real, com efeito, que não pode ser definido senão em relação ao simbólico e ao imaginário, está fora de

\section{Professor G. Bruère-Dawson, comunicação pessoal.}


simbolização. Ele está onde o sujeito não o encontra, lá onde o real vem se chocar contra ele.

É justamente neste caso que se trata de pensar o silêncio, na experiência de Magali, como enfatizando o objeto ausente da voz. Entre o silêncio mudo do impartilhável e a necessidade igualmente impetuosa de partilhar - "Vir falar-lhe me permitiu melhor me fazer compreender e me tirou de meu isolamento", disse ela um dia - manifesta-se inicialmente o silêncio como revelando a hiância de um espaço não-simbolizado. Em face desta prova radical que assinala a entrada progressiva na psicose - verdadeira queda sem fim que orienta o sujeito entre sobrevivência e falta de sucessão - inscreve-se a vergonha como fundamentalmente (h)ontológica. Em outras palavras, no sentido lacaniano, tratase aqui da "vergonha de viver" que faz eco à "vergonha de ser" no sentido heideggeriano: "O próprio ser”, nos diz Lacan (1969-1970), "traz consigo a vergonha, a vergonha de ser" (p. 211). Pela vergonha como modo de apelo em relação ao outro, o sujeito testemunharia, portanto, permanecer sujeito no sentido em que a vergonha lhe permitiria experimentar-se como tal.

Conclusão

Minha discussão insistiu, por meio de uma evocação clínica, sobre esta co-ocorrência entre vergonha, psicose e laço social. Tratava-se, nesta perspectiva, de considerar o conjunto das noções dinâmicas em jogo que, em sua polissemia, revelam um dos paradoxos maiores da vergonha, a saber: ela ameaça o sujeito com o desaparecimento, apesar de mantê-lo sujeito. Da solidão com a qual o sujeito - preso a uma desorganização psicótica - se encontra brutalmente confrontado, a vergonha seria ao mesmo tempo a causa e, como sentimento social, lhe permitiria continuar a se experimentar como tal. É justamente neste ponto que a vergonha constituiria uma experiência subjetiva contraditória. Ela coloca de alguma forma em suspenso o sujeito entre a exclusão e a integração, entre a experiência de desamparo e o laço social, entre a incerteza narcísica e a confirmação existencial.

Neste sentido, as questões da dinâmica intra e intersubjetiva articulam-se a uma dimensão destrutiva da vergonha - ela desencadeia a subjetividade - e a experiência contraditória do mal-estar como modo de apelo ao olhar do outro manutenção da identidade subjetiva - em seu caráter fundamentalmente paradoxal. Substituindo o sentimento de vergonha na própria história do desenvolvimento psíquico, delimitando-a a uma de suas fases, designando-a como seqüela arcaica assinalada por seu discurso na psicose, a interpretação teórica e clínica visaria 


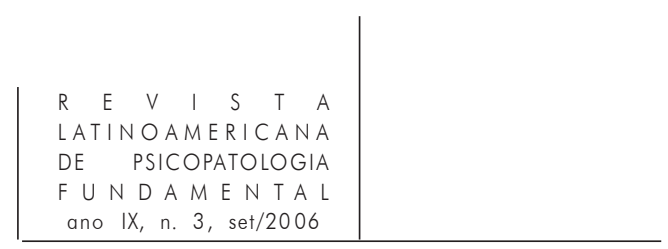

aqui postular a expressão da vergonha como o meio de ser reconhecido como sujeito e objeto diferenciado. No entanto, esta análise nos deixa com um enigma, já que um tipo de paradoxo parece existir entre a vergonha como traço no tempo anterior à entrada na psicose, e a vergonha que não deixa traço na experiência psicótica. Terminarei citando Magali, quando diz, ao final das entrevistas iniciadas um ano antes:

"Esta lucidez sobre a minha vergonha é benéfica e ao mesmo tempo dolorosa... mas, para escolher, prefiro a lucidez à ignorância.”

\section{Referências}

Aulagnier, P. Telle une zone sinistrée. Adolescence, Paris: GREUPP, v. 2, n. 1, p. 9-21, 1984.

Assoun, P.-L. Le préjudice et l'idéal. Pour une clinique sociale du trauma. Paris: Anthropos, 1999.

Freud, S. (1900). L'interprétation des rêves. Paris: PUF, 1967. p. 213.

JACOBI, B. De la honte à la plainte. In: Victime-Agresseur Tome 1 - Le traumatisme sexuel et ses devenirs. Lecques: Les Editions du Champ Social, 2000.

Lacan, J. (1953-1954). Le séminaire. Livre I. Les écrits techniques de Freud. Paris: Seuil, 1975.

(1960). Subversion du sujet et dialectique du désir dans l'inconscient freudien. In Écrits. Paris: Seuil, 1966.

(1960-1961). Le séminaire. Livre VIII. Le transfert. Paris: Seuil, 1991. 1991.

(1969-1970). Le séminaire. Livre XVII. L'envers de la psychanalyse. Paris: Seuil,

Miollan, C. Inceste, une écoute post-traumatique. Cliniques Méditerranéennes: Exile et migrations dans la langue. Toulouse: Érès, n. 55/56, p. 163, 1998.

Scotto Di Vetтimo, D. (2001). Métapsychologie et clinique de la honte: son statut, ses manifestations, son traitement psychothérapique. 2001. Tese (doctorat en Sciences Humaines). Universidade de Nice Sophia-Antinopolis, França.

Scotto Di Vetтimo, D.; JacoBi, B. Du tourment de la honte à la préoccupation narcissique. Psychologie Clinique. Rupture des liens, Clinique des altérités, Paris: L’Harmattan, n. 16, p. 112, 2003. 
Este artículo propone un debate crítico de la problemática de la vergüenza considerada desde la vertiente social donde hace síntoma y donde viene a señalar la herida del ideal. En efecto, la vergüenza es en primer lugar un sentimiento social: aparece generalmente en reacción a la mirada del otro y señala el fracaso de la confirmación narcisista. La hipótesis propuesta postula que en el trabajo clínico junto a sujetos confrontados con una experiencia psicótica, la expresión de la vergüenza como prueba ontológica de la mirada del Otro, constituiría una tentativa del sujeto de probarse como tal. Esta reflexión insiste, a través de una evocación clínica, en la concomitancia entre vergüenza, psicosis y vínculo social.

Palabras clave: Vínculo social, narcisismo, psicosis, sentimiento de vergüenza

Cet article propose une discussion critique de la problématique de la honte considérée sur le versant social où elle fait symptôme et où elle vient marquer la blessure d'idéal. En effet, la honte est d'abord un sentiment social: elle apparaît le plus souvent en réaction au regard d'autrui et vient marquer l'échec de la confirmation narcissique. L'hypothèse postule que dans le travail clinique auprès de sujets confrontés à une expérience psychotique, l'expression de la honte comme épreuve ontologique au regard de l'Autre constituerait une tentative du sujet de s'éprouver comme tel. Cette réflexion insiste, à travers une évocation clinique, sur cette co-occurrence entre honte, psychose et lien social.

Mots clés: Lien social, narcissism, psychos, sentiment de honte

This article presents a critical discussion of the problem of shame, or embarassment, considered from the social point of view, where shame represents a symptom and indicates a wounded ideal. Shame is thus a social emotion, since it usually appears as a reaction to the gaze of the other and indicates a failure in narcissistic confirmation. This hypothesis suggests that in clinical work with subjects who have had psychotic experiences the expression of shame, as ontological proof of the gaze of the Other, constitutes an attempt by the subject to prove her/himself as such. From the clinical point of view, this reflection points to the mutual presence of shame, psychosis and social relations.

Key words: Social relation, narcissism, psychosis, emotion of shame 